\title{
Measuring air movement in small spaces: understanding air movement in historic bookshelves
}

\author{
Morena Ferreira $^{\mathrm{a}^{*}}$, Josep Grau-Bovéa ${ }^{\text {, Nigel Blades }}{ }^{\mathrm{b}}$, Hector Altamirano $^{\mathrm{c}}$ \\ aUCL Institute for Sustainable Heritage, London, United Kingdom \\ bNational Trust for England, Wales and Northern Ireland, London, United Kingdom \\ cUCL Institute for Environmental Design and Engineering, London, United Kingdom
}

\begin{abstract}
The National Trust has tested ventilation holes in bookshelves to encourage air movement behind books as a possible strategy to improve the environment in these microclimates. This could be used as a preventive measure for mould development. Air movement was measured in historic bookshelves to understand what causes air movement and the impact of ventilation holes on the shelves behind books. Three libraries in National Trust properties were used as case studies. It was found that pressure differential and stack effect are two mechanisms contributing to the air velocities measured. However, several variables are believed to influence air movement in these small spaces, and further research is needed to understand its influence on mould development.

Peer-review under the responsibility of the organizing committee of the ICMB21.
\end{abstract}

Keywords: Air movement; Historic buildings; Preventive conservation; Microclimates; Mould.

\section{Introduction}

Mould development is responsible for the biological deterioration of historic materials such as books [1]. Environments with higher relative humidity levels contribute to mould development [2], and an example are microclimates formed behind books in bookshelves in historic buildings. It is believed that increasing air motion in shelves through the use of ventilation holes can eliminate these microclimates, which is a strategy being tested by the National Trust [3]. The aim is to understand what causes air movement behind books, as well as drawing parallels between the measured air movement and previous records of mould development. This study focuses on historic bookshelves of National Trust properties in the United Kingdom.

\section{Methodology}

For this study, three libraries with different mould incidences were selected and are located in the following historic properties: Charlecote Park - with a constant presence of mould in the library, Blickling Hall - with episodes of mould growth in the past and Ham House - with no record of mould in the library. Air movement, relative humidity and temperature were monitored in a bookshelf of each property over two periods of six days, during summer and winter. Shelves no higher than $2 \mathrm{~m}$ were selected as monitoring points to capture the impact of visitors moving in the libraries. Each property shelves have different configurations: Blickling Hall has $2.5 \mathrm{~cm}$ holes along the back of the shelves, Ham House has a continuous $1.5 \mathrm{~cm}$ gap in the same area and Charlecote Park does not have intentional openings. An anemometer was placed on each bookshelf, books were removed to fit the bulky equipment and the space was then covered to mimic a continuous row of books. Air movement in the room was simultaneous monitored in front of each bookshelf, at the same height (Fig. 1a). Ultrasonic anemometers WindSonic ${ }^{\mathrm{TM}}$ were used. Wind velocities collected by the Met Office for the monitored periods were used to compare with the air movement behaviour in the room and bookshelves.

Figure 1. set up used for monitoring air movement in Charlecote Park library: an anemometer on a tripod in the room is placed in front of the anemometer in the bookshelf (white area in bookshelf).

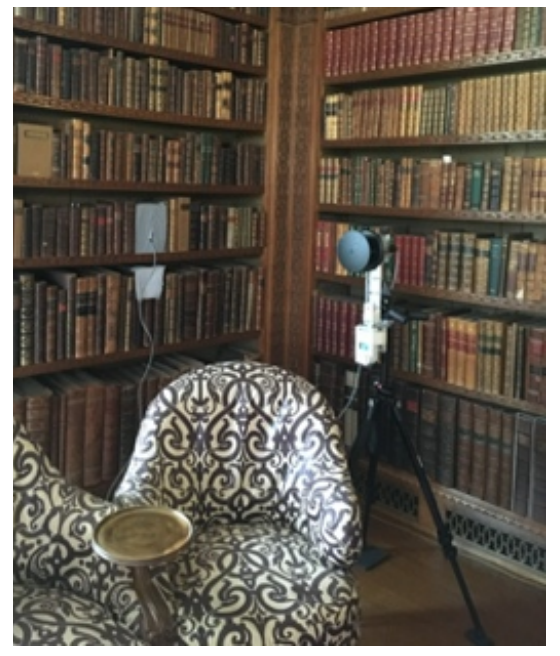

* Corresponding author. 004407721907151. Morena.Ferreira.16@ucl.ac.uk

(C) The Author(s). This is an open access article distributed under the terms of the Creative Commons Attribution License (CC BY) 4.0 https:// creativecommons.org/licenses/by/4.0/, which permits unrestricted use, distribution and reproduction in any medium, provided the original author and source are credited. DOI: 10.14293/ICMB210022 


\section{Results and discussion}

It was found that two mechanisms of forced convection are responsible for the air movement measured behind books: stack effect (caused by a temperature differential) and pressure differentials (e.g., people circulating, opening windows). This can be seen in the summer monitoring data from Charlecote Park which shows some correlation between the peaks of air movement measured in the room and the increase of air movement detected in the bookshelf (Fig. 2a). In this case, a pressure differential is believed to be responsible for the motion detected, very likely caused by the opening of the property which includes opening and closing external doors for access of people. However, the periods of time when velocities increase and its magnitude do not always correlate and so further analysis is necessary. The shelves monitored in this property have no ventilation gaps. Ham House presents a different scenario, where an increase of air velocities in the bookshelf does not coincide with the same behaviour in the room. In fact, when air movement increases in the room, the opposite happens in the bookshelf (Fig. 2b). It was found that the air movement at Ham House during this period can be explained by the presence of a stack effect, when using an adapted equation for the draft flow for this data, explaining the air movement behaviour both on the shelf and in the room. In this property, the shelves are open behind the books with $1.5 \mathrm{~cm}$ continuous gaps. In Blickling Hall, using the same adapted equation, part of the air movement seems to be explained by a stack effect but not all of the monitored days.

The velocities measured in the bookshelf in Ham House were the lowest in the three case studies, but it is at the same time the case study with no records of mould growth. The lower air velocities can be explained by fewer visitors in the library, Ham House is the property with fewer visitors during the monitoring periods, while Charlecote Park has more visitors, explaining higher air velocities in the room which air movement peaks coincide with visiting times. No correlation was found between the air movement in the bookshelves and external wind speeds for the same period in all case studies.

(a)

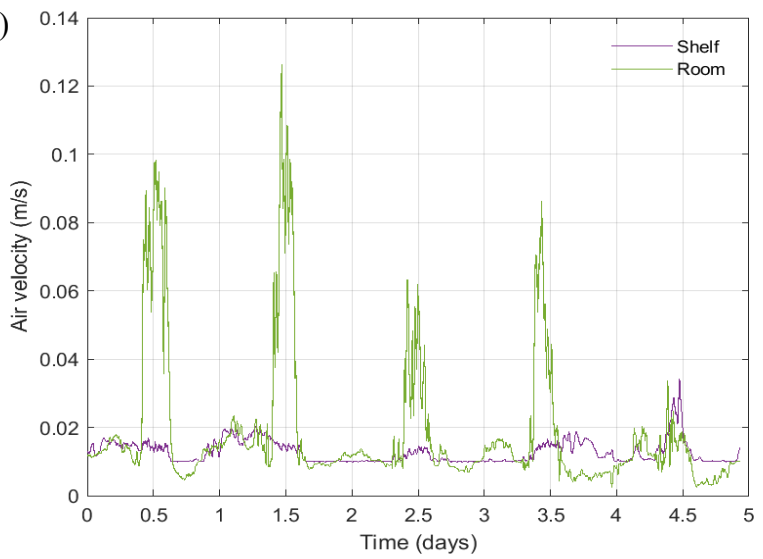

(b)

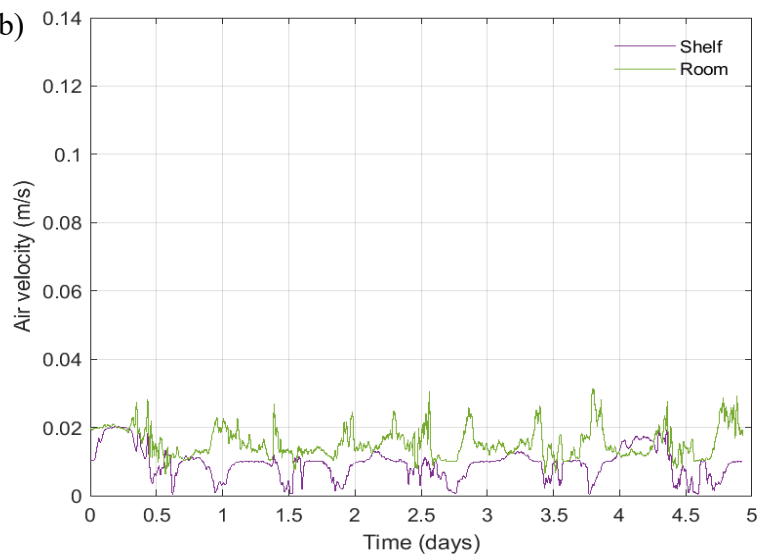

Figure 2. (a) moving average of air movement monitored in the bookshelf and the room in Charlecote Park during five days in the summer; (b) moving average of air movement monitored in the bookshelf and the room in Ham House during five days in the summer.

\section{Conclusions}

The air movement scenario of each case study seems to be different with possible causes being the holes present in the bookshelves and the amount of movement by visitors in the rooms. In the historic bookshelves studied, air movement seems to be generated by a pressure differential caused by people moving in the room, and by a stack effect. Both mechanisms may be present simultaneously, influencing air movement behind books on different scales. Understanding which mechanisms are present is important to determine how air movement could be controlled in such spaces and used as a preventive conservation measure. It is also important to consider that several variables seem to influence air movement in these spaces, such as the geometry of bookshelves, books and the environmental control used in the rooms, all of which should be considered in future studies. Determining a correlation between air movement and mould development could help better understand air movement as a prevention mechanism for mould development in bookshelves in historic buildings.

\section{References}

[1] Florian M.-L. (1997). Heritage Eaters. James \& James (Science Publishers) Ltd, London.

[2] Valentin N, Garcia R, De Luis O, Maekawa S. 1998. Microbial Control in Archives, Libraries and Museums by Ventilation Systems. Restaurator, (19), 85107.

[3] Curteis T. (2016). Environmental survey and monitoring of the library and analysis of environmental test results. Blickling Hall, Norfolk, National Trust. 